\title{
Axiomatization of Aristotelian Syllogistic Logic Based on Generalized Quantifier Theory
}

\author{
Xiaojun Zhang ${ }^{1,2}$ \\ ${ }^{1}$ Institute of Logic and Information, Sichuan Normal University, Chengdu, China \\ ${ }^{2}$ Fujian Provincial Key Laboratory of Brain-Like Intelligent Systems, Xiamen University, Xiamen, China
}

Email address:

zhangxj566@163.com

\section{To cite this article:}

Xiaojun Zhang. Axiomatization of Aristotelian Syllogistic Logic Based on Generalized Quantifier Theory. Applied and Computational Mathematics. Vol. 7, No. 3, 2018, pp. 167-172. doi: 10.11648/j.acm.20180703.23

Received: June 17, 2018; Accepted: August 1, 2018; Published: August 13, 2018

\begin{abstract}
Syllogistic reasoning is important due to the prominence of syllogistic arguments in human reasoning, and also to the role they have played in theory of reasoning from Aristotle onwards. Aristotelian syllogistic logic is a formal study of the meaning of four Aristotelian quantifiers and of their properties. This paper focuses on logical system based on syllogistic reasoning. It firstly formalized the 24 valid Aristotle's syllogisms, and then has proven that the other 22 valid Aristotle's syllogisms can be derived from the syllogisms 'Barbara' AAA-1 and 'Celarent' EAE-1 by means of generalized quantifier theory and set theory, so the paper has completed the axiomatization of Aristotelian syllogistic Logic. This axiomatization needs to make full use of symmetry and transformable relations between/among the monotonicity of the four Aristotelian quantifiers from the perspective of generalized quantifier theory. In fact, these innovative achievements and the method in this paper provide a simple and reasonable mathematical model for studying other generalized syllogisms. It is hoped that the present study will make contributions to the development of generalized quantifier theory, and to bringing about consequences to natural language information processing as well as knowledge representation and reasoning in computer science.
\end{abstract}

Keywords: Generalized Quantifier Theory, Aristotelian Syllogisms, Aristotelian Quantifiers, Axiomatization

\section{Introduction}

Most reasoning theorists agree that the appropriate theory of inference should be provided by formal logic. The logic can provide a computational level or competence theory of reasoning, in other words, the theory of what inferences people should draw ([1], p. 192). Syllogistic reasoning is the most intensively researched and theoretically important task in the study of logical reasoning [2-5]. It is important due to the prominence of syllogistic arguments in human reasoning, and also to the role they have played in theory of reasoning from Aristotle onwards. The completeness of various formulation of syllogistic logic has already been shown, for example by in Łukasiewicz [6], by in Martin [7] and Moss [8]. Syllogistic logic has already been studied from the perspective of generalized quantifier theory [9-12]. Although there are many other articles about Aristotelian syllogisms [13]-[18], we are not aware of axiomatization of Aristotelian syllogisms by means of generalized quantifier theory, and so this is a goal of the paper.

This paper focuses on logical system based on syllogistic reasoning. A syllogism is a particular instantiation of a syllogistic scheme. One can interpret a syllogism such as the following example:

All students in class 3 are running on the playground.

Some students in red clothes are students in class 3.

Some students in red clothes are running on the playground. The syllogism means that the sentences above the line semantically entail the one below the line. In other words, in every context or model in which All students in class 3 are running on the playground and Some students in red clothes are students in class 3 are true, it must be the case that Some students in red clothes are running on the playground is also true.

A syllogism has two premises, one conclusion. It has the form $Q_{1}(P, M) \wedge Q_{2}(M, S) \Rightarrow Q_{3}(S, P)$, where $S$ is the set of things that the subject term denotes, $P$ is the set of things that the predicate term expresses, and $M$ is the set of things that the middle term signifies, each of $Q_{1}, Q_{2}, Q_{3}$ in a Aristotelian 
syllogism is one of the four Aristotelian quantifiers all, some, no, not all. The above example can be denoted by all $(M, P) \wedge$ some $(S, M) \Rightarrow$ some $(S, P)$. The other cases are similar.

Aristotelian syllogistic logic is a formal study of the meaning of the four Aristotelian quantifiers and of their properties. For example, the validity of the syllogism not all $(S$, $M) \wedge$ all $(P, M) \Rightarrow$ not all $(S, P)$ show that the quantifier not all is monotone decreasing in the second argument. Aristotle derived all valid syllogisms from the two syllogisms 'Barbara' (i.e. all $(M, P) \wedge$ all $(S, M) \Rightarrow \operatorname{all}(S, P))$ and 'Celarent' (i.e. no $(M, P) \wedge$ no $(S, M) \Rightarrow \operatorname{all}(S, P))([19]$, p. 228]). In other words, Aristotelian syllogistic logic can be axiomatized on the basis of 'Barbara' and 'Celarent'. How can one do that? The writer of this paper applies generalized quantifier theory to formalize Aristotelian syllogisms, and then to axiomatize the logic. To full appreciate the paper below, one will need basic familiarity with the language of first-order logic, with generalized quantifier theory, and with elementary set theoretic terminology.

\section{Preliminaries}

If $Q$ is a generalized quantifiers, there are three important forms of its negation that appear in natural and logical languages, that is, outer negation $\neg Q$, inner negation $Q \neg$, and dual negation $Q^{d}$. There are two important generalized quantifiers in English, i.e., type $\langle 1\rangle$ and type $\langle 1,1\rangle$. These two kinds of quantifiers are ubiquitous in the natural languages. The four Aristotelian quantifiers all, some, no, not all are just four instances of type $\langle 1,1\rangle$ generalized quantifiers. It is important to recognize that the latter are more basic than the former in the natural languages ([20], p. 12). The type $\langle 1\rangle$ quantifiers are properties of sets of things. The type $\langle 1,1\rangle$ quantifiers are binary relations between sets of things or stuff.

For instance, a quantified sentence 'All cars of our brothers are running quickly' states that all $(S, P)$ holds, where $S$ is the set of cars of our brothers, $P$ is the set of things that are running quickly, and all is a relation between sets. The type $\langle 1$, 1) quantifier all is a particularly simple relation to describe: it is just the subset relation $\subseteq$, i.e., $S \subseteq P$. In other words, all signifies the inclusion relation.

By the same token, each of the other Aristotelian quantifiers stands for a particular binary relation between properties, i.e., a binary relation between of individuals. When $S, P$ are arbitrary sets, these relations can be given in standard set-theoretic notations as the following:

Definition 1:

(1) all $(S, P) \Leftrightarrow S \subseteq P$; (2) no (S,P) $\Leftrightarrow S \cap P=\varnothing$;

(3) some $(S, P) \Leftrightarrow S \cap P \neq \varnothing$; (4) not all $(S, P) \Leftrightarrow S-P \neq \varnothing$.

Definition 2: three forms of negation for type $\langle 1,1\rangle$ quantifiers

Let $E$ be a given universe, and $S, P \subseteq E$, for a type $\langle 1,1\rangle$ quantifier $Q$,

(1) $(\neg Q)_{E}(S, P) \Leftrightarrow \operatorname{not} Q_{E}(S, P)$;

(2) $(Q \neg)_{E}(S, P) \Leftrightarrow Q_{E}(S, E-P)$;

(3) $\left(Q^{d}\right)_{E}(S, P) \Leftrightarrow \neg(Q \neg)_{E}(S, P) \Leftrightarrow(\neg Q)_{E} \neg(S, P)$.

For example, $\neg$ all $=$ not all, $\neg$ some $=$ no, all $\neg=$ no, some $\neg$
$=$ not all, all a $^{\mathrm{d}}=$ some, $n o^{\mathrm{d}}=$ not all. The modern square of opposition (in which all is used without existential import) is composed of the four quantifiers $Q, \neg Q, Q \neg$, and $Q^{d}$. For example, the Aristotelian square of opposition is composed of the four Aristotelian quantifiers, all, not all, no and some as in figure 1 below. The modern square of opposition is closed under these forms of negation, namely, applying any number of these operations to a quantifiers in the square will not lead outside it ([20], p. 12), for example, $\neg\left(\right.$ some $\left.^{d}\right) \neg=\left(\right.$ some $\left.^{d}\right) \neg$ $=$ all $\neg=$ no.

Definition 3: monotonicity for type $\langle 1,1\rangle$ quantifiers

Let $E$ be a given universe, and $S, S^{\prime}, P, P^{\prime} \subseteq E$, for a type $\langle 1$, 1) quantifier $Q$,

(1) $Q_{E}$ is right monotone increasing (denoted by Mon $\uparrow$ or $Q \uparrow)$ iff the following holds:

if $P \subseteq P^{\prime} \subseteq E$, then $Q_{E}(S, P) \Rightarrow Q_{E}\left(S, P^{\prime}\right)$.

(2) $Q_{E}$ is right monotone decreasing (denoted by Mon $\downarrow$ or $Q \downarrow)$ iff the following holds:

if $P \subseteq P^{\prime} \subseteq E$, then $Q_{E}\left(S, P^{\prime}\right) \Rightarrow Q_{E}(S, P)$.

(3) $Q_{E}$ is left monotone increasing (denoted by $\uparrow$ Mon or $\uparrow Q$ ) iff the following holds:

if $S \subseteq S^{\prime} \subseteq E$, then $Q_{E}(S, P) \Rightarrow Q_{E}\left(S^{\prime}, P\right)$.

(4) $Q_{E}$ is left monotone decreasing (denoted by $\downarrow$ Mon or $\downarrow Q$ ) iff the following holds:

if $S \subseteq S^{\prime} \subseteq E$, then $Q_{E}\left(S^{\prime}, P\right) \Rightarrow Q_{E}(S, P)$.

These local notions can be immediately extended to the global case: $Q$ is right (or left) increasing (or decreasing) if each $Q_{E}$ is.

For example,

(1) All cars of our brothers are running quickly. $\Rightarrow$ All cars of our brothers are running.

Then one can say that all is right monotone increasing, denoted by all $\uparrow$.

(2) No cars of our brothers are running. $\Rightarrow$ No cars of our brothers are running quickly.

Then one can say that no is right monotone decreasing,

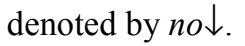

(3) Some black cars of our brothers are running. $\Rightarrow$ Some cars of our brothers are running.

Then one can say that some is left monotone increasing, denoted by $\uparrow$ some.

(4) All cars of our brothers are running. $\Rightarrow$ All black cars of our brothers are running.

Then one can say that all is left monotone decreasing, denoted by $\downarrow$ all.

The (right or left) monotonicity behavior of a type $\langle 1,1\rangle$ quantifier completely determines the monotonicity behavior of the other negation quantifiers in its square of opposition, that is, as the following Fact 1 ([20], pp. 170-171).

Fact 1: Let $Q$ be any type $\langle 1,1\rangle$ quantifier:

(1) $Q$ is $M o n \uparrow$ iff $\neg Q$ is $M o n \downarrow$;

(2) $Q$ is $M o n \uparrow$ iff $Q \neg$ is $M o n \downarrow$;

(3) $Q$ is $M o n \uparrow$ iff $Q^{d}$ is $M o n \uparrow$;

(4) $Q$ is Mon $\downarrow$ iff $\neg Q$ is Mon $\uparrow$;

(5) $Q$ is Mon $\downarrow$ iff $Q \neg$ is Mon $\uparrow$;

(6) $Q$ is Mon $\downarrow$ iff $Q^{d}$ is $M o n \downarrow$;

(7) $Q$ is $\uparrow$ Mon iff $\neg Q$ is Mon $\downarrow$; 
(8) $Q$ is $\uparrow$ Mon iff $Q \neg$ is $\uparrow$ Mon;

(9) $Q$ is $\uparrow$ Mon iff $Q^{d}$ is $\downarrow$ Mon;

(10) $Q$ is $\downarrow$ Mon iff $\neg Q$ is $\uparrow$ Mon;

(11) $Q$ is $\downarrow$ Mon iff $Q \neg$ is $\downarrow$ Mon;

(12) $Q$ is $\downarrow$ Mon iff $Q^{d}$ is $\uparrow$ Mon.

Proof For (1), let $E$ be a given universe, let $S, P$, and $P^{\prime}$ be any subsets of $E$. If a type $\langle 1,1\rangle$ quantifier $Q$ is $M o n \uparrow$, this means that $Q$ is right monotone increasing, then for all $P \subseteq P^{\prime} \subseteq E, Q_{E}(S, P) \Rightarrow Q_{E}\left(S, P^{\prime}\right)$ according to the clause (1) of Definition 3, thus for all $P \subseteq P^{\prime} \subseteq E, \neg Q_{E}\left(S, P^{\prime}\right) \Rightarrow \neg Q_{E}(S, P)$, therefore $\neg Q$ is right monotone decreasing by the clause (2) of Definition 3. That is, $\neg Q$ is Mon $\downarrow$, as desired.

The proof of the other direction is similar. If $\neg Q$ is Mon $\downarrow$, this means that $\neg Q$ is right monotone decreasing, then for all $P \subseteq P^{\prime} \subseteq E, \neg Q_{E}\left(S, P^{\prime}\right) \Rightarrow \neg Q_{E}(S, P)$ according to the clause (2) of Definition 3, then for all $P \subseteq P^{\prime} \subseteq E, Q_{E}(S, P) \Rightarrow Q_{E}\left(S, P^{\prime}\right)$, hence $Q$ is right monotone increasing by the clause (1) of Definition 3. That is, $Q$ is $M o n \uparrow$, just as desired.

The proofs of the other cases are similarly to this.

As a result of the four Aristotelian quantifiers have been found to be just four instances of generalized quantifiers, therefore, the conclusion of Fact 1 is also suitable for the four quantifiers. The monotonicity of the four Aristotelian quantifies and their interrelations are as in Figure 1.

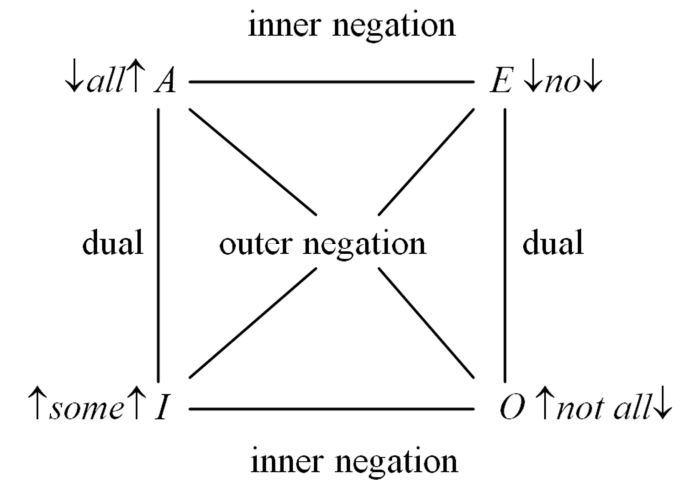

Figure 1. Monotonicity of the four Aristotelian quantifies and their interrelations.

Definition 4: symmetry for type $\langle 1,1\rangle$ quantifiers

Let $Q$ be a type $\langle 1,1\rangle$ quantifier, $Q$ is symmetric if and only if for all universes $E$, and $S, P \subseteq E, Q_{E}(S, P) \Leftrightarrow Q_{E}(P, S)$.

For example, Some doctors are women. $\Rightarrow$ Some women are doctors.

Some women are doctors. $\Rightarrow$ Some doctors are women.

Therefore some is symmetric according to Definition 4.

\section{Formalization of Aristotelian Syllogisms}

In order to keep the symbolic language concise, the proposition 'All $S$ are $P$ ' is denoted by all $(S, P)$ and called by $A$ proposition, 'No $S$ are $P$ ' is denoted by $n o(S, P)$ and called by $E$ proposition, 'Some $S$ are $P$ ' is denoted by some $(S, P)$ and called by $I$ proposition, and 'Not all $S$ are $P$ ' is denoted by no $(S, P)$ and called by $O$ proposition.
According to the possible configurations of variables, Aristotelian syllogisms can be grouped into four different 'figures'(as shown in Table 1):

Table 1. Four different 'figures' of Aristotelian syllogisms.

\begin{tabular}{llll}
\hline (1) first figure & (2) second figure & (3) third figuree & (4) fourth figure \\
\hline $\mathrm{Q}_{1}(\mathrm{M}, \mathrm{P})$ & $\mathrm{Q}_{1}(\mathrm{P}, \mathrm{M})$ & $\mathrm{Q}_{1}(\mathrm{M}, \mathrm{P})$ & $\mathrm{Q}_{1}(\mathrm{P}, \mathrm{M})$ \\
$\mathrm{Q}_{2}(\mathrm{~S}, \mathrm{M})$ & $\mathrm{Q}_{2}(\mathrm{~S}, \mathrm{M})$ & $\mathrm{Q}_{2}(\mathrm{M}, \mathrm{S})$ & $\mathrm{Q}_{2}(\mathrm{M}, \mathrm{S})$ \\
$\mathrm{Q}_{3}(\mathrm{~S}, \mathrm{P})$ & $\mathrm{Q}_{3}(\mathrm{~S}, \mathrm{P})$ & $\mathrm{Q}_{3}(\mathrm{~S}, \mathrm{P})$ & $\mathrm{Q}_{3}(\mathrm{~S}, \mathrm{P})$ \\
\hline
\end{tabular}

Here $Q$ can be chosen among the quantifiers all, some, no, not all, so there are $4 \times 4 \times 4 \times 4=256$ syllogisms. A syllogism is valid if each instantiation of $S, M$ and $P$ verifying the premises also verifies the conclusion. For what choices of quantifiers are the above figures valid? For example, in the second figure, if we let $Q_{I}=$ all and $Q_{2}=Q_{2}=n o$, then the syllogism all $(P, M) \wedge$ no $(S, M) \Rightarrow$ no $(S, P)$ is valid. The syllogism can be denoted as $A E E-2$. Similarly, the syllogism 'Barbara' all $(M, P) \wedge$ all $(S, M) \Rightarrow$ all $(S, P)$ can be denoted as $A A A-1$.

Let $\mathrm{E}$ be any given universe. Now the 24 valid Aristotelian syllogisms can be formalized as follows ([21]):

(01) $A A A-1: \operatorname{all}_{E}(M, P) \wedge \operatorname{all}_{E}(S, M) \Rightarrow \operatorname{all}_{E}(S, P)$

(02) AAI-1: $\operatorname{all}_{E}(M, P) \wedge \operatorname{all}_{E}(S, M) \Rightarrow \operatorname{some}_{E}(S, P)$

(03) $A I I-1: \operatorname{all}_{E}(M, P) \wedge \operatorname{some}_{E}(S, M) \Rightarrow \operatorname{some}_{E}(S, P)$

(04) EIO-1: $\operatorname{no}_{E}(M, P) \wedge \operatorname{some}_{E}(S, M) \Rightarrow \operatorname{notall}_{E}(S, P)$

(05) $E A E-1: n o_{E}(M, P) \wedge \operatorname{all}_{E}(S, M) \Rightarrow n o_{E}(S, P)$

(06) EAO-1: $\operatorname{no}_{E}(M, P) \wedge \operatorname{all}_{E}(S, M) \Rightarrow \operatorname{notall}_{E}(S, P)$

(07)AEE-2: $\operatorname{all}_{E}(P, M) \wedge n o_{E}(S, M) \Rightarrow n o_{E}(S, P)$

(08) $A E O-2: \operatorname{all}_{E}(P, M) \wedge n o_{E}(S, M) \Rightarrow \operatorname{notall}_{E}(S, P)$

(09) $E A E-2: \operatorname{no}_{E}(P, M) \wedge \operatorname{all}_{E}(S, M) \Rightarrow n o_{E}(S, P)$

(10) $E A O-2: \operatorname{no}_{E}(P, M) \wedge \operatorname{all}_{E}(S, M) \Rightarrow \operatorname{notall}_{E}(S, P)$

(11) $E I O-2: \operatorname{no}_{E}(P, M) \wedge \operatorname{some}_{E}(S, M) \Rightarrow \operatorname{notall}_{E}(S, P)$

(12) $A O O-2: \operatorname{all}_{E}(P, M) \wedge \operatorname{notall}_{E}(S, M) \Rightarrow \operatorname{notall}_{E}(S, P)$

(13) $E I O-3: \operatorname{no}_{E}(M, P) \wedge \operatorname{some}_{E}(M, S) \Rightarrow \operatorname{notall}_{E}(S, P)$

(14) OAO-3: $\operatorname{notall}_{E}(M, P) \wedge \operatorname{all}_{E}(M, S) \Rightarrow \operatorname{notall}_{E}(S, P)$

(15) $\operatorname{IAI}_{-3}$ : $\operatorname{some}_{E}(M, P) \wedge \operatorname{all}_{E}(M, S) \Rightarrow \operatorname{some}_{E}(S, P)$

(16) $A I I-3: \operatorname{all}_{E}(M, P) \wedge \operatorname{some}_{E}(M, S) \Rightarrow \operatorname{some}_{E}(S, P)$

(17) $A A I-3: \operatorname{all}_{E}(M, P) \wedge \operatorname{all}_{E}(M, S) \Rightarrow \operatorname{some}_{E}(S, P)$

(18) $E A O-3: \operatorname{no}_{E}(M, P) \wedge \operatorname{all}_{E}(M, S) \Rightarrow \operatorname{notall}_{E}(S, P)$

(19) $I A I-4: \operatorname{some}_{E}(P, M) \wedge \operatorname{all}_{E}(M, S) \Rightarrow \operatorname{some}_{E}(S, P)$

(20) EIO-4: $\quad$ no $_{E}(P, M) \wedge \operatorname{some}_{E}(M, S) \Rightarrow$ not all $_{E}(S, P)$

(21) $A A I-4: \operatorname{all}_{E}(P, M) \wedge \operatorname{all}_{E}(M, S) \Rightarrow \operatorname{some}_{E}(S, P)$

(22) $A E E-4: \operatorname{all}_{E}(P, M) \wedge n o_{E}(M, S) \Rightarrow n o_{E}(S, P)$

(23) $A E O-4: \operatorname{all}_{E}(P, M) \wedge n o_{E}(M, S) \Rightarrow \operatorname{notall}_{E}(S, P)$

(24) $E A O-4: n_{E}(P, M) \wedge \operatorname{all}_{E}(M, S) \Rightarrow \operatorname{notall}_{E}(S, P)$

In Aristotelian syllogisms, it must be emphasized that the quantifier all in $A$ proposition is used with existential import. So all $(S, P)$ in effect means that all $S \mathrm{~s}$ are $P$ and there are some $S$ s. Therefore the quantifier all in (02), (06), (08), (10) and (23) above is used with existential import, otherwise the corresponding syllogisms are invalid.

\section{Axiomalization of Aristotelian Syllogistic Logic}

The 24 above valid Aristotelian syllogisms can be derived from the two syllogisms 'Barbara' and 'Celarent' ([9], p. 228). 
Is that true? How to prove? If it is true and the conclusion is proved, then one can say that she has completed the axiomatization of Aristotelian syllogistic logic. We are not aware of proof this conclusion by means of generalized quantifier theory, and so this is a goal of the paper.

The validities of the two syllogisms 'Barbara' and 'Celarent' are proved by means of generalized quantifier theory.

Proof: (1) The syllogism 'Barbara' form is $\operatorname{all}_{E}(M, P) \wedge$ $\operatorname{all}_{E}(S, M) \Rightarrow \operatorname{all}_{E}(S, P)$. Suppose that $\operatorname{all}_{E}(M, P)$ and $\operatorname{all}_{E}(S$, $M)$ hold, then $\operatorname{all}_{E}(M, P) \Leftrightarrow M \subseteq P \subseteq E$ and $\operatorname{all}_{E}(S, M) \Leftrightarrow$ $S \subseteq M \subseteq E$ according to the clause (1) of Definition 1. Since $M \subseteq P \subseteq E$ and $S \subseteq M \subseteq E$, and hence $S \subseteq P \subseteq E$. So it follows that $S \subseteq P \subseteq E \Leftrightarrow \operatorname{all}_{E}(S, P)$ according to the clause (1) of Definition 1 again. This proves the claim that $\operatorname{all}_{E}(M, P) \wedge \operatorname{all}_{E}(S, M) \Rightarrow$ $\operatorname{all}_{E}(S, P)$, as desired.

(2) The validity of the syllogism 'Celarent' can be similarly proved. The syllogism 'Celarent's form is no $(M, P) \wedge$ no $(S$, $M) \Rightarrow$ all $(S, P)$. If $n o_{E}(M, P)$ and all $_{E}(S, M)$ hold, then $n o_{E}$ $(M, P) \Leftrightarrow M \cap P=\varnothing$ and $\operatorname{all}_{E}(S, M) \Leftrightarrow S \subseteq M \subseteq E$ by the clause (2) and (1) of Definition 1 respectively. So it follows that $M \cap P=\varnothing$ and $S \subseteq M \subseteq E$, then $S \cap P=\varnothing$. Hence $S \cap P=\varnothing \Leftrightarrow n o_{E}(S$, $P$ ) according to the clause (2) of Definition 1. So $n o_{E}(M, P) \wedge$ $\operatorname{all}_{E}(S, M) \Rightarrow n o_{E}(S, P)$, just as desired.

Now the paper tries to axiomatize Aristotlian syllogistic logic by means of the above Definition 1-4 and Fact 1.

\subsection{The Valid Syllogisms Can Be Derived from the Syllogism 'Barbara' AAA-1}

That the syllogism 'Barbara' $A A A-1$ is valid means that all $_{E}$ $(M, P) \wedge \operatorname{all}_{E}(S, M) \Rightarrow \operatorname{all}_{E}(S, P)$. It follows that $\operatorname{all}_{E}(M, P) \Leftrightarrow$ $M \subseteq P \subseteq E$ according to the clause (1) of Definition 1. Hence that $\operatorname{all}_{E}(M, P) \wedge \operatorname{all}_{E}(S, M) \Rightarrow \operatorname{all}_{E}(S, P)$ is equivalent to that if $M \subseteq P \subseteq E$, then $\operatorname{all}_{E}(S, M) \Rightarrow \operatorname{all}_{E}(S, P)$, and therefore all is right monotone increasing by the clause (1) of Definition 3. That is to say that the syllogism $A A A-1$ is valid if and only if that all is right monotone increasing. Then the following 15 Aristotlian syllogisms can be derived from the validity of the syllogism 'Barbara' $A A A-1$.

(1) It is easy to observe that all $=\neg$ not all by the clause (1) of Definition 2. So one has the following: all is right monotone increasing, iff, not all is right monotone decreasing according to the clause (1) of Fact 1 , iff, if $P \subseteq M \subseteq E$, then not $\operatorname{all}_{E}(S, M) \Rightarrow \operatorname{not}^{a l l}(S, P)$ by the clause (2) of Definition 3, iff, $\operatorname{all}_{E}(P, M) \wedge \operatorname{notall}_{E}(S, M) \Rightarrow \operatorname{not} \operatorname{all}_{E}(S, P)$ by the clause (1) of Definition 1. Therefore the syllogism $A O O-2$ is valid, just as desired.

(2) One can similarly prove that the syllogism $A O O-2$ is valid. One has that all $=n o \neg$ by Definition 2 . Then one has the following: all is right monotone increasing, iff, no is right monotone decreasing by virtue of the clause (2) of Fact 1, iff, if $P \subseteq M \subseteq E$, thus $n o_{E}(S, M) \Rightarrow n o_{E}(S, P)$ by the clause (2) of Definition 3, iff, $\operatorname{all}_{E}(P, M) \wedge n o_{E}(S, M) \Rightarrow n o_{E}(S, P)$ by the clause (1) of Definition 1. Hence the syllogism $A E E-2$ is valid.

(3) It is easy to observe that $n_{E}(S, P) \Rightarrow$ not $\operatorname{all}_{E}(S, P)$ since the $O$ proposition is subalternate to the $E$ proposition. And (2) has proven that $\operatorname{all}_{E}(P, M) \wedge n o_{E}(S, M) \Rightarrow n o_{E}(S, P)$. Therefore $\operatorname{all}_{E}(P, M) \wedge n o_{E}(S, M) \Rightarrow \operatorname{not} \operatorname{all}_{E}(S, P)$. That is to say that the syllogism $A E O-2$ is valid.

(4) One can easily check that $n o(S, M) \Leftrightarrow n o(M, S)$, i.e., no is symmetric by Definition 4. If one substitutes $n o_{E}(M, S)$ for $n o_{E}(S, M)$ in ' $\operatorname{all}_{E}(P, M) \wedge n o_{E}(S, M) \Rightarrow n o_{E}(S, P)$ ' proved in (2), it follows that $\operatorname{all}_{E}(P, M) \wedge n o_{E}(M, S) \Rightarrow n o_{E}(S, P)$. Therefore the syllogism $A E E-4$ is valid.

(5) The proof of validity of $A E O-4$ is similar to that of $A E O-2$ in (3). It is easy to observe that $n o_{E}(S, P) \Rightarrow \operatorname{not~all}_{E}(S$, $P)$. And the paper has proven that $\operatorname{all}_{E}(P, M) \wedge n o_{E}(M, S) \Rightarrow$ $n o_{E}(S, P)$ in (4). Hence $\operatorname{all}_{E}(P, M) \wedge n o_{E}(M, S) \Rightarrow \operatorname{notall}_{E}(S$, $P)$. In other words, the syllogism $A E O-4$ is valid.

(6) The proof of validity of $A I I-1$ is similar to that of $A O O-2$ in (1). It is easy to show that all $=$ some $^{\mathrm{d}}$ all by the clause (3) of Definition 2. Hence it can be proved the following: all is right monotone increasing, iff, some is right monotone increasing according to the clause (3) of Fact 1, iff, if $M \subseteq P \subseteq E$, then some $_{E}(S, M) \Rightarrow$ some $_{E}(S, P)$ by the clause (1) of Definition 3, iff, $\operatorname{all}_{E}(M, P) \wedge \operatorname{some}_{E}(S, M) \Rightarrow \operatorname{some}_{E}(S, P)$ by the clause (1) of Definition 1. That is to say that the syllogism AII-1 is valid, as desired.

(7) It is known to that $(\neg r \wedge p \rightarrow \neg q)$ can be derived from ( $p$ $\wedge q \rightarrow r)$ in which $p, q$ and $r$ are proposition variables. It follows that $\neg$ some $_{E}(S, P) \wedge \operatorname{some}_{E}(S, M) \Rightarrow \neg \operatorname{all}_{E}(M$, $P)$ )can be derived from ' $\operatorname{all}_{E}(M, P) \wedge \operatorname{some}_{E}(S, M) \Rightarrow$ some $_{E}$ $(S, P)$ ' proved in (6). Then since $M, S$, and $P$ are any variables, this is semantically equivalent to that $\neg \operatorname{some}_{E}(M, P) \wedge$ $\operatorname{some}_{E}(M, S) \Rightarrow \neg \operatorname{all}_{E}(S, P)$ by changing variables. It is clear that $\neg$ some $=$ no and $\neg$ all $=$ not all, hence $n o_{E}(M, P) \wedge$ $\operatorname{some}_{E}(M, S) \Rightarrow \operatorname{not} \operatorname{all}_{E}(S, P)$. This means that the syllogism $E I O-3$ is valid.

(8) The proof of validity of EIO-4 is similar to that of $A E E-4$ in (4). It is intuitively clear that $n o_{E}(M, P) \Leftrightarrow n o_{E}(P, M)$, that is, no is symmetric by Definition 4 . Now if one substitutes $n o_{E}(P, M)$ for $n o_{E}(M, P)$ in ' $n o_{E}(M, P) \wedge \operatorname{some}_{E}(M, S) \Rightarrow$ not $\operatorname{all}_{E}(S, P)$ ' proved in (7), it follows that $n o_{E}(P, M) \wedge \operatorname{some}_{E}(M$, $S) \Rightarrow$ not $\operatorname{all}_{E}(S, P)$. So the syllogism EIO-4 is valid, as desired.

(9) The proof of validity of EIO-1 is similar to that of EIO-4 in (8). It is easily to check that $\operatorname{some}_{E}(M, S) \Leftrightarrow \operatorname{some}_{E}(S, M)$, i.e., some is symmetric. Now if one substitutes $\operatorname{some}_{E}(S, M)$ for $\operatorname{some}_{E}(M, S)$ in ' $n o_{E}(M, P) \wedge \operatorname{some}_{E}(M, S) \Rightarrow \operatorname{notall}_{E}(S, P)$ ' proved in (7), it follows that $n o_{E}(M, P) \wedge \operatorname{some}_{E}(S, M) \Rightarrow$ not $\operatorname{all}_{E}(S, P)$. Hence the syllogism $E I O-1$ is valid, as desired.

(10) One can observe that no is symmetric since it satisfies the scheme $n o_{E}(M, P) \Leftrightarrow n o_{E}(P, M)$ as above. If one replaces $n o_{E}(M, P)$ by $n o_{E}(P, M)$ in ' $n o_{E}(M, P) \wedge \operatorname{some}_{E}(S, M) \Rightarrow$ not $\operatorname{all}_{E}(S, P)$ ' proved in (9), it follows that $n o_{E}(P, M) \wedge \operatorname{some}_{E}(S$, $M) \Rightarrow$ not $^{a l l}(S, P)$. In other words, the syllogism $E I O-2$ is valid.

(11) The proof of validity of $A A I-4$ is similar to that of $E I O-3$ in (7). It is can be showed that $\neg$ not $\operatorname{all}_{E}(S, P) \wedge \operatorname{all}_{E}(P$, $M) \Rightarrow \neg n o_{E}(M, S)$ can be derived from $\operatorname{all}_{E}(P, M) \wedge n o_{E}(M, S)$ $\Rightarrow \operatorname{not} \operatorname{all}_{E}(S, P)$. Therefore $\operatorname{all}_{E}(S, P) \wedge \operatorname{all}_{E}(P, M) \Rightarrow$ some $_{E}(M, S)$ since $\neg$ not all $=$ all and $\neg$ no $=$ some. It is intuitively clear that $\operatorname{all}_{E}(P, M) \wedge \operatorname{all}_{E}(M, S) \Rightarrow \operatorname{some}_{E}(S, P)$. Hence the syllogism $A A I-4$ is valid, as desired.

(12) The proof of validity of $A A I-1$ is similar to that of 
$A E O-2$ in (3). It is intuitively clear that $\operatorname{all}_{E}(S, P) \Rightarrow \operatorname{some}_{E}(S$, $P$ ) since the $I$ proposition is subalternate to the $A$ proposition. Then the validity of $\operatorname{all}_{E}(M, P) \wedge \operatorname{all}_{E}(S, M) \Rightarrow \operatorname{some}_{E}(S, P)$ can be derived from that of $A A A-1 \operatorname{all}_{E}(M, P) \wedge \operatorname{all}_{E}(S, M) \Rightarrow \operatorname{all}_{E}(S$, $P)$. In other words, the syllogism $A A I-1$ is valid.

(13) The proof of validity of $E A O-3$ is similar to that of $E I O-3$ in (7). That $\neg \operatorname{some}_{E}(S, P) \wedge \operatorname{all}_{E}(S, M) \Rightarrow \neg \operatorname{all}_{E}(M, P)$ is implied by that $\operatorname{all}_{E}(M, P) \wedge \operatorname{all}_{E}(S, M) \Rightarrow \operatorname{some}_{E}(S, P)$ proved in (12). Then $\left.\operatorname{no}_{E}(M, P)\right) \wedge \operatorname{all}_{E}(M, S) \Rightarrow \operatorname{not}_{\operatorname{all}}(S, P)$ since $\neg$ some $=$ no and $\neg$ all $=$ not all. It is semantically equivalent to that $\left.\operatorname{no}_{E}(M, P)\right) \wedge \operatorname{all}_{E}(M, S) \Rightarrow \operatorname{not}_{\operatorname{all}}(S, P)$ by changing variables. This shows that the syllogism EIO-3 is valid.

(14) The proof of validity of $A I I-3$ is similar to that of $A E E-4$ in (4). One can observe that some is symmetric since $\operatorname{some}_{E}(S, M) \Leftrightarrow \operatorname{some}_{E}(M, S)$. If one replaces $\operatorname{some}_{E}(S, M)$ by $\operatorname{some}_{E}(M, S)$ in ' $\operatorname{all}_{E}(M, P) \wedge \operatorname{some}_{E}(S, M) \Rightarrow \operatorname{some}_{E}(S, P)$ ' proved in (6), it follows that $\operatorname{all}_{E}(M, P) \wedge \operatorname{some}_{E}(M, S) \Rightarrow$ some $_{E}(S, P)$. So the syllogism $A I I-3$ is valid, just as desired.

(15) The proof of validity of $E A O-4$ is similar to that of EIO-3 in (7). That $\neg \operatorname{some}_{E}(S, P) \wedge \operatorname{all}_{E}(P, M) \Rightarrow \neg a l_{E}(M, S)$ can be implied by that $\operatorname{all}_{E}(P, M) \wedge \operatorname{all}_{E}(M, S) \Rightarrow \operatorname{some}_{E}(S, P)$ proved in (11). Therefore $n_{E}(S, P) \wedge \operatorname{all}_{E}(P, M) \Rightarrow \operatorname{notall}_{E}(M$, $S)$ since $\neg$ some $=$ no and $\neg$ all $=$ not all. Hence $\left.n o_{E}(P, M)\right) \wedge$ $\operatorname{all}_{E}(M, S) \Rightarrow \operatorname{not}_{\operatorname{all}}(S, P)$ by changing variables. That is, the syllogism $E A O-4$ is valid, as desired.

\subsection{The Valid Syllogisms Can Be Derived from the Syllogism 'Celarent' EAE-1}

That the syllogism 'Celarent' EAE-1 is valid means that $n o_{E}(M, P) \wedge \operatorname{all}_{E}(S, M) \Rightarrow n o_{E}(S, P)$. It follows that $\operatorname{all}_{E}(S, M)$ $\Leftrightarrow S \subseteq M \subseteq E$ according to the clause (1) of Definition 1. Then that $n o_{E}(M, P) \wedge \operatorname{all}_{E}(S, M) \Rightarrow n o_{E}(S, P)$ is equivalent to that if $S \subseteq M \subseteq E$, then $n o_{E}(M, P) \Rightarrow n o_{E}(S, P)$, and therefore no is left monotone decreasing by the clause (4) of Definition 3 . That is to say that the syllogism $E A E-1$ is valid if and only if that no is left monotone decreasing. Then the following 7 Aristotlian syllogisms can be derived from the validity of the syllogism 'Celarent' EAE-1.

(16) The proof of validity of $I A I-3$ is similar to that of $A O O-2$ in (1). It follows that no $=\neg$ some according to the clause (1) of Definition 2. So one has the following: no is left monotone decreasing, iff, some is left monotone increasing according to the clause (1) of Fact 1, iff, if $M \subseteq S \subseteq \mathrm{E}$, then some $_{E}(M, P) \Rightarrow \operatorname{some}_{E}(S, P)$ by the clause (3) of Definition 3, iff, $\operatorname{some}_{E}(M, P) \wedge \operatorname{all}_{E}(M, S) \Rightarrow \operatorname{some}_{E}(S, P)$ by the clause (1) of Definition 1. Therefore the syllogism $I A I-3$ is valid, as desired.

(17) The proof of validity of IAI-4 is similar to that of $A E E-4$ in (4). The paper has proven that $\operatorname{some}_{E}(M, P) \Leftrightarrow$ $\operatorname{some}_{E}(P, M)$ as above. If one replaces $\operatorname{some}_{E}(S, M)$ by $\operatorname{some}_{E}(M, S)$ in ' $\operatorname{all}_{E}(M, P) \wedge \operatorname{some}_{E}(S, M) \Rightarrow \operatorname{some}_{E}(S, P)$ ' proved in (6), it follows that $\operatorname{all}_{E}(M, P) \wedge \operatorname{some}_{E}(M, S) \Rightarrow$ some $_{E}(S, P)$. So the syllogism $I A I-4$ is valid.

(18) The proof of validity of $O A O-3$ is similar to that of $A O O-2$ in (1). It is easy to check that $n o \neg=$ not all according to the clause (2) of Definition 2. So it follows the following: no is left monotone decreasing, iff, not all is left monotone increasing according to the clause (8) of Fact 1, iff, if $M \subseteq S \subseteq E$, then not $\operatorname{all}_{E}(M, P) \Rightarrow$ not $\operatorname{all}_{E}(S, P)$ by the clause (4) of Definition 3, iff, $\operatorname{not}_{\operatorname{all}}(M, P) \wedge \operatorname{all}_{E}(M, S) \Rightarrow \operatorname{notall}_{E}(S, P)$ by the clause (1) of Definition 1. Hence the syllogism $O A O-3$ is valid, as desired.

(19) The proof of validity of $E A E-2$ is similar to that of $A E E-4$ in (4). It follows that $n o_{E}(M, P) \Leftrightarrow n o_{E}(P, M)$ as above. If we substitute $n o_{E}(P, M)$ for $n o_{E}(M, P)$ in $E A E-1$ ' $n o_{E}(M, P)$ $\wedge \operatorname{all}_{E}(S, M) \Rightarrow n o_{E}(S, P)$ ', one can obtain that $n o_{E}(P, M) \wedge$ $\operatorname{all}_{E}(S, M) \Rightarrow n o_{E}(S, P)$. Hence the syllogism $I A I-4$ is valid.

(20) The proof of validity of $E A O-2$ is similar to that of $A E O-2$ in (3). It follows that $n_{E}(S, P) \Rightarrow$ not $\operatorname{all}_{E}(S, P)$ as above. And (19) has proven that $n o_{E}(P, M) \wedge \operatorname{all}_{E}(S, M) \Rightarrow$ $n o_{E}(S, P)$. Then $\operatorname{no}_{E}(P, M) \wedge \operatorname{all}_{E}(S, M) \Rightarrow \operatorname{not}^{a l l}(S, P)$. Therefore the syllogism $E A O-2$ is valid.

(21) The proof of validity of $E A O-1$ is similar to that of $E A O-2$ in (20). It is clear that $\operatorname{no}_{E}(S, P) \Rightarrow \operatorname{not} \operatorname{all}_{E}(S, P)$. Then that $\operatorname{no}_{E}(P, M) \wedge \operatorname{all}_{E}(S, M) \Rightarrow \operatorname{not}^{a} l_{E}(S, P)$ can be derived from $E A E-1 n o_{E}(M, P) \wedge \operatorname{all}_{E}(S, M) \Rightarrow n o_{E}(S, P)$. That is to say that the syllogism $E A O-1$ is valid.

(22) The proof of validity of $A A I-3$ is similar to that of $E I O-3$ in (7). That $\neg$ not $\operatorname{all}_{E}(S, P) \wedge \operatorname{all}_{E}(S, M) \Rightarrow \neg n o_{E}(P, M)$ can be implied by that $\operatorname{no}_{E}(P, M) \wedge \operatorname{all}_{E}(S, M) \Rightarrow \operatorname{not}_{\operatorname{all}}(S, P)$ proved in (20). Then $\operatorname{all}_{E}(S, P) \wedge \operatorname{all}_{E}(S, M) \Rightarrow \operatorname{some}_{E}(P, M)$ since $\neg$ not all $=$ all and $\neg$ no $=$ some. It is equivalent to that $\left.\operatorname{all}_{E}(M, P)\right) \wedge \operatorname{all}_{E}(M, S) \Rightarrow \operatorname{some}_{E}(S, P)$ by changing variables. Hence the syllogism $A A I-3$ is valid.

Now the paper has derived the other 22 valid Aristotelian syllogisms just from the two syllogisms $A A A-1$ and $E A E-1$. In other words, it has completed the axiomatiztion of Aristotelian syllogistic logic, just as desired.

\section{Conclusion}

This paper firstly formalized the 24 valid Aristotle's syllogisms, and then has proven that the other 22 valid Aristotle's syllogisms can be derived from the syllogisms $A A A-1$ and $E A E-1$ by means of generalized quantifier theory and set theory, so the paper has completed the axiomatization of Aristotelian syllogistic logic. In fact, these innovative achievements and the method in this paper provide a simple and reasonable mathematical model for studying other generalized syllogisms. It is hoped that the present study will make contributions to the development of generalized quantifier theory, and to bringing about consequences to natural language information processing as well as knowledge representation and reasoning in computer science.

As it turns out, generalized quantifiers are an extremely versatile syntactic and semantic tool. As a future work, it would be interesting to formally study the validity of generalized syllogisms, and then to formally discuss on the validity of discourse reasoning in natural languages nested by two or more Aristotelian syllogisms or generalized ones. 


\section{Acknowledgements}

This work was supported by the National Social Science Foundation of China under Grant No. 16BZX081.

\section{References}

[1] N. Chater and M. Oaksford, the probability Heuristics model of syllogistic reasoning, Cognitive Psychology, Vol. 38, 1999, pp. 191-258.

[2] G. Patzig, Aristotle's Theory of the Syllogism, J. Barnes (trans.), Dordrecht: D. Reidel, 1969.

[3] L. S. Moss, Syllogistic logics with verbs, Journal of Logic and Computation, Vol. 20, No. 4, 2010, pp. 947-967.

[4] P. Murinová P and V. Novák, A formal theory of generalized intermediate syllogisms, Fuzzy Sets and Systems, Vol. 186, 2012, pp. 47-80.

[5] J. Endrullis, and L. S. Moss, Syllogistic logic with 'Most', in V. de Paiva et al. (eds. ), Logic, Language, Information, and Computation, 2015, pp. 124-139.

[6] J. Łukasiewicz, Aristotle's Syllogistic from the Standpoint of Modern Formal Logic, Clarendon Press, Oxford, 1951.

[7] J. N. Martin, Aristotle's natural deduction reconsidered, History and Philosophy of Logic, Vol. 18, No. 1 1997, pp. 1-15.

[8] L. S. Moss, Completeness theorems for syllogistic fragments, in F. Hamm and S. Kepser (eds.), Logics for Linguistic Structures, Mouton de Gruyter, Berlin, 2008, pp. 143-173.

[9] J. van Benthem, Questions about quantifiers, Journal of Symbol Logic, Vol. 49, No. 2, 1984, pp. 443-466.

[10] D. Westerståhl, Aristotelian syllogisms and generalized quantifiers, Studia Logica, Vol. XLVII, No. 4, 1989, pp. 577-585.
[11] Xiaojun Zhang, A Study of Generalized Quantifier Theory, Xiamen University Press, 2014. (in Chinese).

[12] Xiaojun Zhang, A Study of Properties of Generalized Quantifiers, Ph.D. dissertation, Chinese Academy of Social Sciences, 2011. (in Chinese).

[13] N. Ivanov, and D. Vakarelov, A system of relational syllogistic incorporating full Boolean reasoning, Journal of Logic, Language and Information, 2012 (12), pp. 433-459.

[14] I. P. Hartmann, The relational syllogistic revisited, Perspectives on Semantic Representations for Textual Inference, CSLI Publications, 2014, pp. 195-227.

[15] Xudong Hao, On the fourth figure of Aristotle's syllogisms, Journal of Northwest University (Philosophy and Social Sciences), 2015 (6), pp. 142-146. (in Chinese).

[16] L. S. Moss, Syllogistic Logic with Cardinality Comparisons, Springer International Publishing, 2016.

[17] Shuai Li, and Xiaoming Ren, A New exploration on inductive logic of Aristotle, Journal of Chongqing University of Technology (Social Sciences), 2016 (7), pp. 6-11. (in Chinese).

[18] Baoxiang Wu, Aristotel's Syllogisms and its Extensions, Sichuan Normal University, Master's Dissertation, 2017. (in Chinese).

[19] D. Westerståhl, Quantifiers in formal and natural languages, in D. M. Gabbay and F. Guenthner (eds.), Handbook of Philosophical Logic, Vol. 14, 2007, pp. 227-242.

[20] S. Peters, and D. Westerståhl, Quantifiers in Language and Logic, Claredon Press, Oxford, 2006.

[21] Xiaojun Zhang, Sheng Li, Research on the formalization and axiomatization of traditional syllogisms, Journal of Hubei University (Philosophy and social sciences), No. 6, 2016, pp. 32-37. (in Chinese). 